\title{
Faktor-Faktor yang Mempengaruhi Implementasi SIMSETGIS (Sistem Informasi Manajemen Aset Berbasis WebGIS (Geographics Information System)) di Badan Pengelolah Keuangan Dan Aset Daerah Kota Kendari
}

\author{
Yenny Suryaningsih ${ }^{1}$; Sartono $^{2}$; Asrul Jaya ${ }^{3}$ \\ ${ }^{123}$ Universitas Halu Oleo, yennysuryaningsih97@gmail.com
}

\begin{abstract}
Abstrak
Penelitian ini bertujuan untuk mengetahui dan mendeskripsikan faktor-faktor yang mempengaruhi implementasi SIMSETGIS (Sistem Informasi Manajemen Aset Berbasis WebGIS (Geographics Information System) di Badan Pengelolah Keuangan Dan Aset Daerah (BPKAD) Kota Kendari. Untuk mengetahui tujuan tersebut digunakan metode penelitian kualitatif untuk menggali informasi-informasi dari informan yang bersifat terbuka dan bebas dengan 5 orang informan. Penelitian ini dilakukan pada Badan Pengelolah Keuangan dan Aset Daerah Kota Kendari dengan jenis data berupa data primer dan data sekunder. Instrumen penelitian sendiri dilakukan dengan dokumentasi, wawancara, dan observasi. Hasil penelitian ini menunjukan bahwa dalam faktor-faktor yang mempengaruhi implementasi SIMSETGIS (Sistem Informasi Manajemen Aset Berbasis WebGis (Geografis Information System) di Badan Pengelola Keuangan dan Aset Daerah Kota Kendari, masih ditemukan faktor yang kurang dalam pemberian informasi terutama hal yang berkaitan dengan informasi aset yang masih kurang. Dan jumlah sumberdaya manusia yang masih kurang sehingga dapat menghambat kecepatan dalam pemberian informasi.
\end{abstract}

Kata kunci : BPKAD, Faktor, Implementasi, SIMSETGIS

\begin{abstract}
This study aimed to determine and describe the factors that influenced the implementation of SIMSETGIS (WebGIS-Based Asset Management Information System) at Regional Financial and Asset Management Agency, Kendari City (BPKAD). To find out those objectives, qualitative research method was used to extract information from informants who were open and free. This research was conducted at the Regional Financial and Asset Management Agency, Kendari City with the types of data in the form of primary data and secondary data. The research instruments of this study were documentation, interviews, and observation. The results of this study indicated that in the factors that influenced the implementation of SIMSETGIS (WebGis-Based Asset Management Information System) in the Regional Financial and Asset Management Agency in Kendari City, there were still factors that were lacking in providing information, especially matters relating to information assets that were still lacking. And the amount of human resources that were still lacking so that it could hinder the speed in providing information.
\end{abstract}

Keywords : BPKAD, Factor, Implementation, SIMSETGIS

Pendahuluan

Penggunaan teknologi informasi di berbagai aspek dalam kehidupan khusunya dalam pemerintahan sudah sangat berkembang dengan pesatnya. Ini 
dikarenakan tuntutan kinerja yang harus ditingkatkan salah satunya dalam pengelolaan aset daerah.

Pemerintahan kota Kendari khusunya di kantor Badan Pengelolah Keuangan Dan Aset Daerah (BPKAD) pada saat ini menerapkan sebuah aplikasi Sistem Informasi Manajemen aset yang dapat memberikan data dan informasi wilayah yang akurat tentang aset daerah kepada stakeholders maupun masyarakat, aplikasi ini di sebut dengan SIMSETGIS atau Sistem Informasi Manajemen aset berbasis GIS (Geographics Information System). Simsetgis ini di terapkan oleh BPKAD kota Kendari pada tahun 2016. Aplikasi ini dibuat dengan maksud sebagai database media pengelolaan BMD ( Barang Milik Daerah) terhadap aset-aset pemerintah kota kendari dalam bentuk pemetaan melalu GIS (Geographics Information System).

Sistem Informasi Geografi atau dalam bahasa asingnya Geographics Information System (GIS) adalah suatu sistem informasi yang dirancang untuk bekerja dengan data yang bereferensi spasial atau berkoordinat geografi, atau dengan kata lain, GIS adalah suatu sistem basis data dengan kemampuan khusus untuk menangani data yang bereferensi keruangan (spasial) bersamaan dengan seperangkat operasi kerja (Barus dan Wiradisastra, 2000).

BPKAD selaku SKPD yang diserahkan fungsi penatausahaan aset memperoleh hambatan dan permasalahan akibat adanya keterbatasan kemampuan dalam manajemen aset daerah berdasarkan jenis data atau instrumen kerja yang ada saat ini, permasalahan tersebut antara lain : (1) Fungsi pengawasan, yaitu sulitnya mengetahui kondisi aktual secara visual mengenai aset/barang milik daerah. (2) Fungsi pemeriksaan, yaitu sulitnya menjangkau keseluruhan lokasi aset dengan waktu yang singkat. (3) Fungsi pelaporan, yaitu sulitnya mengidentifikasi jenis dan persebaran lokasi aset daerah dikarenakan format data yang ada hanya menyebutkan lokasi secara tertulis. (4) Fungsi transparansi, yaitu sulitnya memberikan informasi kepada masyarakat tentang keberadaan maupun letak dan kondisi aset yang mudah di mengerti tanpa menimbulkan permasalahan baru antara masyarakat dan pemerintah khususnya akibat perbedaan cara pandang memahami database yang telah disusun oleh pemerintah 
Berdasarkan permasalahan yang diakibatkan oleh beberapa keterbasan yang telah tertuang diatas, maka disini BPKAD mencoba merumuskan dan mengimplementasikan suatu bentuk sistem pengelolaan manajemen aset yang dapat mengakomodir dan meminimalkan hambatan-hambatan yang terjadi saat ini melalui suatu sistem aplikasi berbasis WebGis yang dinamai dengan Sistem Informasi Manajemen Aset Berbasis GIS (SIMSETGIS_KENDARI).

Dalam pemberian informasi yang baik melalui SIMSETGIS dapat dipengaruhi oleh faktor-faktor implementasi seperti yang dikatakan oleh Edward dalam Subarsono (2005:90) bahwa faktor-faktor yang mempengaruhi implementasi yaitu komunikasi yang dapat berupa penyaluran komunikasi, konsistensi komunikasi dan kejelasan komunikasi. Faktor kedua yaitu sumberdaya yang dapat berupa sumberdaya manusia dan sarana prasarana. Faktor ketiga disposisi/sikap, dan struktur birokrasi.

Dengan mengacu pada latar belakang di atas, maka penulis mengangkat judul tentang "Faktor-faktor Yang Mempengaruhi Implementasi SIMSETGIS (Sistem Informasi Manajemen Aset Berbasis WebGIS (Geographics Information System) di Badan Pengelolah Keuangan Dan Aset Daerah Kota Kendari ”. Tujuan penelitian untuk mengetahui dan mendeskripsikan faktor-faktor yang mempengaruhi implementasi SIMSETGIS (Sistem Informasi Manajemen Aset Berbasis WebGIS (Geographics Information System) di Badan Pengelolah Keuangan Dan Aset Daerah Kota Kendari.

\section{Metode}

Penelitian ini menggunakan penelitian kualitatif, metode ini digunakan untuk menggali informasi-informasi dari informan yang bersifat terbuka dan bebas dan diharapkan dapat memberikan gambaran dan realita mengenai faktor-faktor yeng mempengaruhi mplementasi SIMSETGIS (Sistem Informasi Manajemen Aset Berbasis WebGIS (Geographics Information System) di Badan Pengelolah Keuangan Dan Aset Daerah Kota Kendari. Penelitian ini di lakukan pada kantor Badan Pengelolah Keuangan Dan Aset Daerah (BPKAD) kota Kendari Sulawesi 
Tenggara dengan alasan karena BPKAD kota Kendari adalah suatu badan yang menerapkan SIMSETGIS (Sistem Informasi Manajemen Aset berbasi WebGIS (Geographics Information System), sehingga pada penelitian ini ditujukan untuk dapat memperoleh informasi tentang faktor-faktor yang mempengaruhi implementasi SIMSETGIS (Sistem Informasi Manajemen Aset Berbasis WebGIS (Geographics Information System ) di Badan Pengelolah Keuangan dan Aset Daerah Kota Kendari. Adapun subjek penelitian SIMSETGIS (Sistem Informasi Manajemen Aset Berbasis Geographics Information System ) adalah pegawai BPKAD (Badan Pengelolah Keuangan Dan Aset Daerah) Kota Kendari yang terdiri dari 165 orang. Sedangkan informan penelitian sebanyak 5 orang yaitu Kepala Bidang Aset, Admin Simsetgis, Developer atau Programmar SIMSETGIS, Kasubag Bidang Pemanfaatan dan Pengamanan Aset, dan 1 orang staf perencanaa program dan laporan keuangan. Dalam pelaksanaan penelitian ini penulis menggunakan teknik analisis data bersifat deskriptif kualitatif, dimana gambaran atau fakta-fakta berdasarkan data yang terkumpul di lapangan yang berkaitan erat dengan objek penelitian, kemudian dipadukan dan dianalisis secara kualitatif dengan memberikan interpretasi/penafsiran atas fakta-fakta tersebut.

\section{Hasil dan Pembahasan}

\section{Profil Badan Pengelolah Keuangan Dan Aset Daerah Kota Kendari}

Berdasarkan Peraturan Daerah Kota Kendari Nomor 21 Tahun 2009 tentang struktur organisasi dan tata kerja Badan Pengelola Keuangan Daerah Kota Kendari dan Peraturan Daerah Kota Kendari Nomor 11 Tahun 2012 tentang Pembentukan organisasi dan tata kerja Badan Pengelola Keuangan dan Aset Daerah Kota Kendari, yang kemudian diubah berdasarkan Peraturan Daerah Kota Kendari Nomor 5 Tahun 2016 tanggal 17 Oktober 2016 tentang Pembentukan dan Susunan Perangkat Daerah Kota Kendari serta Peraturan Walikota Kendari Nomor 62 Tahun 2016 tentang Kedudukan, Susunan Organisasi, Tugas dan Fungsi Serta Tata Kerja Badan Pengelola Keuagan dan Aset Daerah Kota Kendari

Badan Pengelola Keuangan dan Aset Daerah (BPKAD) berkedudukan sebagai Organisasi Perangkat Daerah (OPD) Kota Kendari yang melaksanakan 
fungsi penunjang urusan pemerintahan bidang keuangan yang dipimpin oleh seorang Kepala Badan yang berada dibawah dan bertanggungjawab kepada Walikota melalui Sekretaris Daerah.

Badan Pengelola Keuangan dan Aset Daerah sebagai Organisasi Perangkat Daerah (OPD) juga sebagai Satuan Kerja Pengelola Keuangan Daerah (SKPKD) yang berfungsi sebagai lembaga fungsional dimana Kepala SKPKD selaku Pejabat Pengelolaan Keuangan Daerah (PPKD) dan Selaku Bendahara Umum Daerah (BUD) memiliki peran sangat strategis dalam pengelolaan administrasi keuangan daerah yang didalamnya terdapat Badan Layanan Umum Daerah (BLUD) selaku Unit Kerja Pengelola dan Bergulir Sesuai dengan Peraturan Daerah Kota Kendari Nomor 5 Tahun 2016 tanggal 17 Oktober 2016 tentang Pembentukan dan Susunan Perangkat Daerah Kota Kendari dan Peraturan Walikota Kendari nomor 62 Tahun 2016 tentang Kedudukan, Susunan Organisasi, Tugas dan Fungsi Serta Tata Kerja Badan Pengelola Keuagan dan Aset Daerah Kota Kendari,berikut ini diuraikan tentang :

\section{a. Kedudukan BPKAD kota Kendari}

Kedudukan Badan Pengelolah Keuangan Dan Aset Daerah Kota Kendari adalah :

1. Badan Pengelola Keuangan dan Aset Daerah Kota Kendari merupakan unsur pelaksana urusan pemerintahan yang menjadi kewenangan daerah.

2. Badan Pengelola Keuangan dan Aset Daerah Kota Kendari dipimpin oleh seorang Kepala Badan yang berada dibawah dan bertanggungjawab kepada Walikota melalui Sekretaris Daerah.

\section{b. Tugas dan fungsi}

Badan Pengelola Keuangan dan Aset Daerah mempunyai tugas membantu Walikota dalam melaksanakan penyusunan dan pelaksanaan kebijakan di bidang keuangan dan aset daerah.

Dalam rangka pelaksanaan tugas pokok, Badan Pengelola Keuangan dan Aset Daerah menyelenggarakan fungsi :

1) Perumusan dan pelaksanaan kebijakan teknis dibidang pengelolaaan Keuangan dan Aset Daerah

2) Penyusunan rancangan APBD dan rancangan perubahan APBD 
3) Pengesahan DPA SKPD/DPPA SKPD

4) Pengelolaan Keuangan dan Aset Daerah

5) Pengendalian pelaksanaan APBD

6) Pelaksanaan Penatausahaan, system akuntansi dan pelaporan keuangan daerah

7) Pelaksanaan kebijakan pedoman pengelolaan serta penghapusan barang milik daerah

8) Penatausahaan Barang Milik Daerah

9) Pelaksanaan fungsi lain yang diberikan oleh Walikota sesuai dengan tugas dan fungsi Badan Pengelola keuangan dan Aset Daerah Kota Kendari

\section{c. Tujuan dan Sasaran BPKAD Kota Kendari}

Badan pengelola keuangan dan asset daerah kota kendari yang diamanahkan dalam melaksanakan kebijakan pengelolaan keuangan dan pengelolaan administrasi asset daerah menyusun tujuan yang ingin dicapai dalam Rencana kerja jangka menengah berdasarkan misi pertama pemerintah kota kendari yaitu "Meningkatkan Kualitas Pelayanan Masyarakat"

Dalam Dokumen Rencana Jangka Menengah Daerah (RPJMD) Kota Kendari tahun 2018-2022 telah disebutkan Tujuan yang ingin dicapai yaitu "Memantapkan Kemampuan Keuangan Daerah Berbasis Teknologi Informasi”. Badan pengelolah keuangan dan aset daerah kota kendari yang diamanahkan dalam melaksanakan kebijakan pengelolaan keuangan dan pengelolaan administrasi asset daerah menyusun sasaran yang ingin dicapai dalam Rencana kerja jangka menengah berdasarkan misi pertama pemerintah kota kendari yaitu "Meningkatkan Kualitas Pelayanan Masyarakat"

Dalam Dokumen Rencana Jangka Menengah Daerah (RPJMD) Kota Kendari tahun 2018-2022 telah disebutkan sasaran yang ingin dicapai yaitu "Meningkatnya kemampuan pengelolaan keuangan dan aset daerah serta sumber penerimaan daerah secara efektif dan efisien berbasis teknologi informasi”

\section{d. Strategi BPKAD Kota Kendari}


Strategi Badan Pengelola Keuangan dan Aset Daerah yang mengacu pada Visi dari Kota Kendari yaitu "Mewujudkan Kota Kendari Kota Layak Huni yang Berbasis Ekologi, Informasi dan Teknologi” dan berdasarkan Misi yang berkenaan dengan tugas pokok dan fungsi yaitu "Meningkatkan Kualitas Pelayanan Masyarakat", maka strategi yang ingin dicapai yaitu "Meningkatkan kemampuan pengelolaan keuangan dan aset daerah secara transparan dan akuntabel berbasis teknologi informasi”

\section{e. Program dan kegiatan BPKAD Kota Kendari}

Berdasarkan hasil analisis terhadap arah kebijakan dan strategis untuk pencapaian tujuan maka dilahirkan suatu program dan kegiatan Prioritas sebagai eksekutor pelaksanaan pencapaian tujuan tersebut. Adapun Program Kerja dan Kegiatan Prioritas Badan Pengelolah Keuangan dan Asset Daerah Kota Kendari adalah :

1. Program Peningkatan Dan Pengembangan Pengelolaan Keuangan Daerah

2. Program Peningkatan Dan Pengembangan Pengelolaan Aset Daerah Program

Sedangkan untuk menunjang berlangsungnya pencapaian kinerja dan berjalannya pelaksanaan tugas pokok dan fungsi pelayanan Badan Pengeola Keuangan dan Aset Daerah kota Kendari dilaksanakan Program dan Kegiatan yang dikategorikan Program dan Kegiatan Rutin sebagai berikut:

1. Program Pelayanan Administrasi Perkantoran

2. Program Peningkatan Sarana Dan Prasarana Aparatur

3. Program Peningkatan Disiplin Aparatur

4. Program Peningkatan Kapasitas Sumber Daya Aparatur

5. Program Peningkatan Pengembangan Sistem Pelaporan Capaian Kinerja Dan Keuangan

6. Program Promosi Pembagunan Dan Informasi Daerah

\section{f. Isu Strategis BPKAD Kota Kendari}

Hasil identifikasi permasalahan berdasarakan aspek kajian tugas pokok dan fungsi yaitu : 1) Peningkatan Kualitas dan askuntabilitas pengelolaan Keuangan, 2) Peningkatan Sistem Pelayanan terhadap Perencanaan, Pelaksanaan dan Pelaporan, dan 3) Peningkatan Pengamanan dan Inventarisasi Aset, maka isu 
strategis (permasalahan prioritas) yang akan ditangani melalui rencana strategis periode 2018-2022 dapat di uraikan sebagai berikut :

1. Peningkatan Sumber daya Aparatur

2. Peningkatan Pengawasan dan Pengendalian

3. Peningkatan Sarana dan Prasarana Kerja

4. Peningkatan hubungan Kemitraan/koordinasi baik secara internal maupun eksternal

5. Perolehan keabsahan/Legalitas kepemilikan aset untuk dimanfaatkan pembangunan sarana dan prasarana kota

6. Pemanfaaan teknologi informatika

\section{Faktor-faktor yang Mempengaruhi Implementasi SIMSETGIS di BPKAD Kota Kendari}

Dalam pelaksanaan suatu kebijakan atau program tentunya terdapat faktor faktor yang dapat mempengaruhi proses implementasi suatu program dimana faktor tersebut dapat membantu dan menghambat implementasi program tersebut.

Penerapan SIMSETGIS yang dilakukan oleh BPKAD Kota Kendari tentunya tidak lepas dari prakondisi yang menjadi faktor pendukungnya. Dari hasil penelitian, berbagai faktor pendukung yang dimiliki untuk menerapkan SIMSETGIS ini adalah sebagai berikut:

\section{a. Komunikasi}

Penerapan program akan berjalan efektif apabila ukuran-ukuran dan tujuan-tujuan penerapan dipahami oleh individu yang bertanggung jawab dalam pencapaian tujuan kebijakan (Edward III dalam Subarsono 2005:90).

- Komunikator

Komunikator merupakan seseorang atau oganisasi yang melakukan penyampaian pesan dan informasi untuk mewujudkan pesan komunikasinya. Yang menjadi komunikator dalam memberikan informasi tentang aset derah kota Kendari melalui SIMSETGIS yaitu pihak BPKAD selaku pengelolah barang daerah.

- Pesan/ informasi

Pesan/ informasi adalah segala sesuatu yang disampaikan oleh komunikator kepada komunikan untuk mewujudkan motif komunikasinya. Pesan 
atau informasi yang diberikan atau disajikan dalam SIMSETGIS yaitu informasi terkait aset pemerintah kota kendari yang di kemas dalam bentuk visual atau gambar, titik kordinat, luas, dan kartu inventarisasi barang daerah berupa data KIB A (Tanah/ kosong tanpa bangunan), KIB C (gedung dan bangunan), dan KIB D (jalan).

- Saluran/ media komunikasi

Saluran komunikasi adalah jalan yang dilalui oleh pesan komunikator agar sampai pada komunikannya. dalam pemberian informasi kepada masyarakat terkait aset pemerintah kota kendari sekarang BPKAD memberikan kemudahan kepada masyarakat maupun stakeholders terkait yang membutuhkan informasi dengan hanya mencari informasi aset melalui jaringan internet dengan membuka halaman Web http://simsetgis.kendarikota.go.id sehingga masyarakat atau pengguna dapat lebih mudah dalam mendapatkan informasi tanpa perlu jauh-jauh datang kekantor BPKAD

- Komunikan

Komunikan adalah seseorang atau pihak yang menerima informasi atau pesan yang disajikan oleh komunikator. Dalam implementasi SIMSETGIS yang menjadi komunikan atau penerima informasi adalah para SKPD, Stakeholders dan masyarakat.

- Efek Komunikasi

Efek komunikasi diartikan sebagai pengaruh yang ditimbulkan pesan komunikator dalam diri komunikannya. Pengaruh dalam diri komunikan dapat berupa seseorang menjadi tahu tentang sesuatu. Dalam penerapan SIMSETGIS efek yang dihasilkan yaitu dapat memberikan kemudahan kepada pengguna layanan dan juga memberikan kemudahan kepada implementator dalam memberikan informasi.

\section{b. Sumberdaya}

Dalam pengelolaan SIMSETGIS sumberdaya yang mengolah yaitu terdapat pada bagian aset kemudian ada sumberdaya manusia khusus yang ditunjuk sebagai admin, yaitu bertugas untuk memasukkan data, menginput, mengubah, dan sebagainya namun pada dasarnya untuk pengelolaan SIMSETGIS masih 
kekurangan sumberdaya dalam melakukan pendataan aset terutama untuk melakukan tracking koordinat. Dalam pelaksanaannya juga disini BPKAD menjalin hubungan kerjasama dengan pihak ketiga yaitu CV. Technos Studio sebagai Web Developer atau Programmer SIMSETGIS yang membuat aplikasi dan membantu jika ada kendala terkait maintenance yang tidak bisa diatasi oleh pihak pengelolah. dalam menjalankan SIMSETGIS selain sumberdaya manusia juga didukung dengan adanya sarana prasarana dan biaya dalm menjalankan program yaitu dalam pelaksanaan SIMSETGIS sarana prasarana yang diberikan sudah cukup baik begitupu dengan biaya.

\section{c. Disposisi/Sikap}

Sikap pegawai BPKAD Kota Kendari menerima dengan baik pelaksanaan SIMSETGIS. Untuk sikap yang diberikan oleh para staff disini juga dibutuhkan alasan mengapa perlu dijalankannya SIMSETGIS sesuai dengan pemahaman masing-masing sehingga dengan adanya kejelasan-kejelasan sikap dan alasan dari para staff maka dapat di bentuk sebuah komitmen yang dapat membantu pelaksanaan SIMSETGIS yang lebih efektif. Bentuk komitmen yang dibangun yaitu untuk mendukung visi kota kendari yang berbasis teknologi dan informasi.

\section{Kesimpulan}

Berdasarkan dari hasil diatas terhadap kondisi yang dijumpai dalam penelitian seperti dibahas dalam bab sebelumnya maka kesimpulan yang dapat ditarik dalam penelitian ini adalah sebagai berikut :

Dalam memberikan informasi melalui SIMSETGIS terdapat faktor-fakor yang mempengaruhi implementasi sehingga memberikan informasi yang optimal yaitu :

1) Komunikasi

Untuk penerapan SIMSETGIS yang optimal di BPKAD Kota Kendari didukung dengan adanyaunsur-unsur komunikasi yaitu :

- Komunikator yaitu pihak dari BPKAD khususnya pada bidang aset yang merupakan pihak yang memberikan informasi data visual aset kota Kendarii melalui SIMSETGIS. 
- Pesan/informasi yaitu penyampaian informasi aset daerah kota Kendari yang dikemas dalam bentuk visual dengan menampilkan data gambar/foto, kartu inventarisasi barang, dan peta yang saat ini berupa data KIB A (tanah), KIB C (gedung) dan KIB D (jalan).

- Saluran/media yaitu penyampaian informasi aset kota Kendari dengan mengakses halaman http://simsetgis.kendarikota.go.id.

- Efek yaitu memberikan kemudahan kepada pengelolah barang maupun pengguna barang dalam memperoleh informasi.

- Komunikan yaitu para stakeholders, SKPD/OPD, dan masyarakat yang merupakan user atau pengguna.

2) Sumberdaya

Sumberdaya yang di miliki oleh BPKAD dalam hal ini sumberdaya manusia yaitu masih kurang dengan banyaknya data aset yang harus di masukkan ke SIMSETGIS salah satunya BPKAD kekurangan sumberdaya untuk melakukan tracking koordinat . Namun untuk sarana dan prasarana sudah cukup baik disini juga BPKAD melengkapi dan memberikan fasilitas khusus yang diperlukan dalam pelaksanaan SIMSETGIS yaitu Server, komputer, jaringan, perangkat lunak, Gps, drawn dan meter.

3) Disposisi/Sikap

Adanya sikap implementator yang setuju dan sangat mendukung pelaksanaan SIMSETGIS sehingga program ini berjalan dengan lancar. Dan juga BPKAD menerapkan komitmen dalam menjalankan SIMSETGIS agar sesuai dan dapat membantu dalam pelaksanaan Visi kota Kendari yang berbasis Teknologi Informasi.

\section{Referensi}

Akib, Haedar. (2010). Implementasi Kebijakan: Apa, Mengapa, dan Bagaimana. Jurnal Administrasi Publik. 1(1):2

Barus B., dan Wiradisastra. (2000). Sistem Informasi Geografi, Laboratorium Penginderaan Jauh dan Kartografi. Institut Pertanian Bogor. 
Davis. Gordon B. (1985). Kerangka Dasar Sistem Informasi Manajemen, Jakarta : Gahalia Indo.

Grindle, M.S. (1980). Politics and Policy Implementation in the ThirdWorld, New Jersey: Princeton University Press.

Hambali. (2010). Inventarisasi Barang Milik Negara. Bandung: Politeknik Negeri.

Hartono, Jogiyanto. (2005). Analisa dan Desain Sistem Informasi: Pendekatan Terstruktur Teori dan Praktik Aplikasi Bisnis.yogyakarta: Andi

Hartono, Jogiyanto. (2008). Analisis dan Desain Sistem Informasi : Pendekatan Terstruktur Teori dan Praktek Aplikasi Bisnis (TH.2008). Yogyakarta: Andi.

Hartono, Jogiyanto. (2000). Pengenalan Komputer : Dasar Ilmu Komputer, Pemograman, Sistem Informasi, dan Intelegensi Buatan. Edisi 3. Yogyakarta : C.V Andi Offset.

Hasting, Nicholas A. Jhon. (2010). Psysical Asset Management.

Husein, Rahmad. Konsep Dasar Sistem Informasi Geografi (Geographich Information System). Kuliah Umum Ilmu Komputer.Com. 2006. Diakses 16 Mei 2008, dari komunitas eLearning IlmuKomputer.Com. http://Ilmukomputer.com.

Kristanto, A. (2008). Perancangan Sistem Informasi dan Aplikasinya. Yogyakarta: Gava Media.

Mitami Dian. (2013). Analisis Penerapan Sistem Informasi Manajemen Daerah (Simda) Keuangan Pada Pemerintah Daerah Kabupaten Pangkep. Skripsi. Jurusan Akuntansi. Fakultas Ekonomi Dan Bisnis. Universitas Hasanuddin: Makassar

Nirwansyah, Anang Widhi. (2016). Dasar Sistem Informasi Geografi dan Aplikasinya Menggunakan ARCGIS. Yogyakarta: Deepublish.

Nuryadin, Ruslan. (2005). Panduan Menggunakan Mapserver. Bandung: Informatika

Sabatier, Paul. (1986). Top down and Bottom up Approaches to Implementation Research, Journal of Public Policy 6, (Jan), h. 21-48.

Siregar, D. D. (2004). Manajemen Aset. Strategi Penataan Konsep Pembangunan Berkelanjutan Secara Nasional dalam Konteks Kepala Daerah Sebagai 
CEO'spada Era Globalisasi dan Otonomi Daerah. PT. Gramedia Pustaka Utama.

Simsetgis, diakses dari, http://simsetgis.kendarikota.go.id/

Subarsono. (2005). Analisa Kebijakan Publik. Yogyakarta: Pustaka Pelajar.

Sugiyono. (2014). Metode Penelitian Pendidikan Pendekatan Kuantitatif,Kualitatif, dan R\&D. Bandung: Alfabeta.

Sugiama.Gima A. (2013). Manajemen Aset Pariwisata Bandung : Guardaya Intimarta.

Sunggono, B. (1994). Hukum dan Kebijaksanaan Publik. Jakarta: Sinar. Gra $\square$ ka.

Undang-Undang Nomor 23 Tahun 2014 Tentang Pemerintah Daerah.

Undang-Undang Nomor 1 Tahun 2004. Tentang Perbendaharaan Negara

Wardhana I, Henry, (2005). Mengelola Aset Kota Jakarta, Jurnal Kajian Pengembangan Perkotaan. 1(1)

Wibawa, Samudra, dkk. (1994). Evaluasi Kebijakan Publik. Jakarta: PT. RajaGrafindo Persada

Yusuf, M. (2015). 8 Langkah Pengelolaan Aset Daerah. Jakarta Selatan: Salemba Empat. 